\title{
Vibrio fluvialis: an emerging human pathogen
}

\author{
Thandavarayan Ramamurthy ${ }^{1}$ *, Goutam Chowdhury ${ }^{1}$, Gururaja P. Pazhani ${ }^{1}$ and Sumio Shinoda ${ }^{2}$ \\ ${ }^{1}$ National Institute of Cholera and Enteric Diseases, Kolkata, India \\ ${ }^{2}$ National Institute of Cholera and Enteric Diseases, Collaborative Research Center of Okayama University for Infectious Diseases in India, Kolkata, India
}

Edited by:

Rita R. Colwell, University of

Maryland, USA

Reviewed by:

Carlos R. Osorio, University of

Santiago de Compostela, Spain

Brian Austin, University of Stirling, UK

*Correspondence:

Thandavarayan Ramamurthy, National Institute of Cholera and Enteric

Diseases, P-33, CIT Road,

Scheme-XM, Beliaghata,

Kolkata-700010, India

e-mail: tramu@vsnl.net
Vibrio fluvialis is a pathogen commonly found in coastal environs. Considering recent increase in numbers of diarrheal outbreaks and sporadic extraintestinal cases, $V$. fluvialis has been considered as an emerging pathogen. Though this pathogen can be easily isolated by existing culture methods, its identification is still a challenging problem due to close phenotypic resemblance either with Vibrio cholerae or Aeromonas spp. However, using molecular tools, it is easy to identify $V$. fluvialis from clinical and different environmental samples. Many putative virulence factors have been reported, but its mechanisms of pathogenesis and survival fitness in the environment are yet to be explored. This chapter covers some of the major discoveries that have been made to understand the importance of $V$. fluvialis.

Keywords: $V$. fluvialis, diarrhea, virulence factors, antimicrobial resistance, molecular typing

\section{INTRODUCTION}

Vibrio fluvialis is a halophilic Gram-negative bacterium, which has a curved cell morphology and polar flagella for motility. The important biochemical features of this organism include conversion of nitrate to nitrite, do not cleave L-lysine or ornithine, activate arginine dihydrolase, produce indole but not acetoin, ferment sucrose, D-mannitol, L-arabinose, maltose, trehalose, D-galactose, and D-galacturonate. Most of the vibrios, including $V$. fluvialis occur widely in the aquatic milieu, mostly in the seas, estuaries and brackish waters. Even though more than 100 spices have been reported in the Genus Vibrio (http://www.bacterio.net/uw/vibrio.html), about 13 of them have been reported to cause several human diseases. Among the pathogenic vibrios, V. alginolyticus, V. cholerae, V. costicola, V. mimicus, V. cincinnatiensis, V. hollisae, V. furnissii, V. parahaemolyticus, V. vulnificus, $V$. carchariae (a junior synonym of $V$. harveyi) and $V$. metschnikovii are clinically important as they cause different types of vibriosis. One of the Vibrio spp., $V$. damselae has now been renamed as "Photobacterium damselae subsp. damselae." The toxigenic V. cholerae, V. parahaemolyticus and V. vulnificus are associated with well-known cholera and diarrhea and extraintestinal infections, respectively. Prevalence of $V$. cholerae in developing countries is mostly related to the breakdown of sanitary conditions and/or due to scarcity of drinking water. On the other hand, infections caused by $V$. parahaemolyticus and other vibrios denote contamination of seafood in many countries, irrespective of their economic conditions.

V. fluvialis is one of the emerging foodborne pathogens all over the world. The distribution of virulence factors and molecular epidemiological features of this pathogen remain mostly unknown. Among the foodborne infections in the United States, there has been a considerable increase $(43 \%)$ in the Vibrio-mediated infections till 2012 compared with the rates reported during 2006-2008 (Centers for Disease Control and Prevention (CDC), 2013). Several recent publications indicate the epidemiological importance of $V$. fluvialis (Chowdhury et al., 2012; Liang et al., 2013).

\section{IDENTIFICATION AND TAXONOMY}

Thiosulfate-citrate-bile salts-sucrose agar (TCBS) has been conventionally used as a selective medium for the isolation of clinically important vibrios. The colony morphology of $V$. fluvialis in this medium remains indistinguishable from $V$. cholerae, i.e., it grows as sucrose fermenting yellow color colonies after direct plating of clinical specimens or after enrichment in alkaline peptone water $(\mathrm{pH}$ 8.0). After preliminary screening in the TCBS, a battery of biochemical testes is essential for the species-specific identification of V. fluvialis. Minimal biochemical tests such as lysine decarboxylase, ornithine decarboxylase, arginine dihydrolase, and $\mathrm{L}$-arabinose are mandatory for the identification of $V$. fluvialis. Without these minimal tests, the identification is incomplete and the isolate will be improperly classified as V. cholerae or Aeromonas spp. In most resource-poor countries, these tests are not methodically performed, which may lead to labeling of $V$. fluvialis as $V$. cholerae. Considering such situation, there is a high possibility that the V. fluvialis could be reported as V. cholerae non-O1, non-O139 or non-agglutinable vibrios (NAGs). It is worth to mention here that $V$. cholerae $\mathrm{O} 1$ and $\mathrm{O} 139$ serogroups can be easily confirmed by slide agglutination with corresponding antiserum.

For the identification of $V$. fluvialis and other vibrios, rapid identification kits must be used with caution as they need additional tests for the final confirmation. While testing the commercially available identification kits, $V$. fluvialis remain as a major challenge with API 20E and Vitek GNI+ systems (Israil et al., 2003; O'Hara et al., 2003). Biochemically, V. furnissii expresses fibrin and mucin hydrolysis but no phosphate or esculin hydrolysis, for which V. fluvialis varied. V. fluvialis, V. furnissii, and V. mimicus are distinctive from $V$. cholerae, as the later exhibit strong mannosesensitive hemagglutination. These test results may have a strong influence in the confirmation of strains. 
Molecular tools such as PCR are useful in the identification of many uncommon vibrios and most of these assays are comparable to the conventional identification methods. The sequence of amplified 16S-23S intergenic spacers (IGSs) has demonstrated 37 ribosomal RNA ( $r r n$ ) operons representing seven different IGS types in different Vibrio spp. with IGS(0), IGS(IA), and IGS(Glu) as major ones. The sequence difference in these IGS types was used to design species-specific primers for PCR for $V$. fluvialis and other vibrios (Lee etal., 2002). In some of the reports, a universal primer PCR that covers conserved regions of bacterial $16 \mathrm{~S}$ rRNA genes followed by denaturing gradient gel electrophoresis (DGGE) was found to be useful in the identification of $V$. fluvialis either as axenic bacteria or mixed with other pathogens (Ji et al., 2004).

Initially, $V$. furnissii was taxonomically assigned with $V$. fluvialis and named as aerogenic biogroup of $V$. fluvialis. Based on DNA relatedness and several biochemical tests, $V$. furnissii has been separated as a new species (Lee et al., 1981; Brenner et al., 1983). In the phylogenetic analysis with several housekeeping genes, V. furnissii and $V$. fluvialis have been linked as close species. The nucleotide comparison of 16S-rRNA, recA, and toxR sequences showed that $V$. furnissii and $V$. fluvialis had $100 \%$ similarity. The gene toxR of $V$. fluvialis had $84 \%$ similarity with $V$. harveyi (Franco and Hedreyda, 2006). With the gyrB, V. cholerae, V. mimicus, V. furnissii, and V. fluvialis shared $93 \%$ sequence similarity.

Toxigenic vibrios have a homolog of the toxRS operon, which regulates the virulence expression. The gene tox $R$ encodes a transcriptional activation domain (TAD), a transmembrane domain (TMD), and a periplasmic domain (PD). Among the vibrios, there is essentially no homology within the region between TAD and TMD. Hence, this region has been used in designing of primers for the species-specific identification of many vibrios. Chakraborty et al. (2006) described a species-specific identification of $V$. fluvialis by PCR targeted to the conserved transcriptional activation and variable membrane tether regions of the tox $R$ gene. The functional virulence genes encoding hemolysin ( $v f h)$, heme-utilization ( $h u p O)$, and central regulation ( $v f p A)$ have been used as targets in an multiplex PCR for the identification of V. cholerae, V. parahaemolyticus, and V. fluvialis, respectively (Vinothkumar etal., 2013). For the detection of clinical vibrios in seafood samples, a multiplex primer-extension reaction (PER) assay targeting the rpoA gene has also been reported (Dalmasso et al., 2009).

Pyrolysis-mass spectrometry with metastable atom bombardment and pattern recognition seemed to be suitable for the identification of $V$. fluvialis and other vibrios (Wilkes et al., 2005). The mass spectra have been generated via an alternative ionization method, metastable atom bombardment followed by component-discriminant analysis. Since the outer membrane protein $\mathrm{K}(\mathrm{OmpK})$ of $V$. fluvialis, $V$. alginolyticus, V. mimicus, $V$. parahaemolyticus, and $V$. vulnificus is highly similar, the antibodies against these proteins have been proposed in the diagnosis ( $\mathrm{Li}$ et al., 2010). The whole cell protein profile using SDS-PAGE was also considered in the identification of clinically important vibrios including $V$. fluvialis (Lee et al., 2012).

Since simple phenotypic diagnostic tests are not available, Chen et al. (1995) used species-specific bacteriophages as a tool for the identification of $V$. fluvialis and with a set of phages, the diagnostic probability of human isolates was more than $84 \%$. At least in one study, the importance of phage-typing of $V$. fluvialis has been demonstrated using six specific bacteriophages with 73\% typability (Suthienkul, 1993). However, availability of these bacteriophages makes this assay technique less popular.

\section{PHENOTYPIC AND GENETIC CHARACTERISTICS OF V. fluvialis}

Based on the somatic antigen variation, several serotypes of V. fluvialis have been identified. Though Shimada et al. (1999) identified more than 50 somatic antigens, the serological based typing of $V$. fluvialis remains non-customary. $V$. fluvialis strains belonging to serogroup O19 possessed the C (Inaba) antigen of $V$. cholerae O1, but not the B (Ogawa) or A (common) antigens (Shimada et al., 1987; Kondo et al., 2000). In the crossed immuno-electrophoresis, antibodies against the oral cholera vaccines containing killed whole cells (WC) of V. cholerae O1 Inaba El Tor reacted with a few strains of $V$. fluvialis (Ciznãr et al., 1989). Presence of shared WC antigens indicates that the oral cholera vaccine could stimulate immunity effectively against other vibrios also. It is known that the antigenic nature of flagella of vibrios is highly homologous. Tassin et al. (1983) and Shinoda et al. (1984) demonstrated independently that anti-L-flagella antisera of $V$. fluvialis did not agglutinate other Vibrio species in the $\mathrm{H}$-agglutination tests. Further studies placed $V$. fluvialis and $V$. furnissii in the same lateral flagellar serogroup-HL8 (Shinoda et al., 1992). However, in practice, serotyping based on $\mathrm{H}$-flagella is also not in use.

A chemotaxonomic study based on sugar composition of the polysaccharide portion of their lipopolysaccharide (LPS) has divided $35 \mathrm{O}$-antigen groups of $V$. fluvialis into 21 chemotypes (Iguchi et al., 1993). This seems to be a unique finding since the D-glycero-D-manno-heptose, and two kinds of uronic acids, i.e., galacturonic and glucuronic acids are rare in Gram-negative bacteria. In addition, 2-keto-3-deoxyoctonate, which is a typical sugar component of Gram-negative bacterial LPS was not detectable in any of the chemotypes.

Of all the molecular typing methods, the pulsed-field gel electrophoresis (PFGE) has proven to be highly useful in tying the bacterial isolates. Unlike $V$. cholerae $\mathrm{O} 1$ and pandemic $V$. parahaemolyticus, the isolates of $V$. fluvialis from acute diarrheal patients exhibited large genetic diversity (Chowdhury et al., 2012, 2013).

\section{PREVALENCE OF $V$. fluvialis IN THE AQUATIC REALM}

Even though the presence of vibrios is mostly documented from coastal environs, the domination of a particular species depends on many physico-chemical and biological factors. In warmer regions like Florida, USA, V. fluvialis was predominantly detected in sediments during winter months (Williams and Larock, 1985). Due to rise in seawater temperature, the identification rate of $\mathrm{V}$. $\mathrm{flu}$ vialis has increased considerably (29\%) in several niches at the Toulon harbor, France (Martin and Bonnefont, 1990). However, in Chesapeake Bay, V. fluvialis infections are always less during winter months, indirectly reflecting its minimal occurrence in 
this season (Hoge et al., 1989). V. fluvialis along with V. vulnificus and V. cholerae non-O1 unusually existed in the Seto Inland Sea of Japan, which is a eutrophic zone with riverine influence (Venkateswaran et al., 1989a). In South East Queensland, Australia, next to $V$. cholerae (10.2\%), V. fluvialis (8.2\%) has been isolated more frequently from river waters, sediments, and plants (Myatt and Davis, 1989).

Due to high load of pollution in the upstream of the river Ganges, presence of $V$. fluvialis $(0.74 \%)$ with other potential pathogens have been detected in several points of Varanasi, India (De et al., 1993). V. fluvialis has also been isolated from natural waters in Myanmar (Oo et al., 1993) and in a wide range of coastal environments of Japan (Uchiyama, 2000). Compared to other vibrios, the recovery of $V$. fluvialis has been high $(41.4 \%)$ from suburban community effluents in South Africa. However, their occurrence was not associated with any season or plankton blooms, but positively correlated with temperature, salinity, and dissolved oxygen (Igbinosa et al., 2011a).

In many investigations, the detection frequency of $V$. fluvialis was very high in marine mollusks, mostly in bivalves, as they accumulate large number of pathogens during the process of filter-feeding. Findings of Kelly and Stroh (1988) from Pacific Northwest showed that oysters are the main source of $V$. fluvialis and other vibrios especially during warmer seasons. In Hong Kong, $V$. fluvialis was one of the important pathogenic vibrios identified in coastal waters and seafood sold in the markets (Chan et al., 1986, 1989). V. fluvialis has been isolated from mussels from Senegal (Schandevyl et al., 1984), Brazil (Matté et al., 1994), bivalves and mud from Costa Rica (García and Antillón, 1990) and cultured fishes from Denmark (Pedersen et al., 1999), copepods from Southern Italy (Dumontet et al., 2000) and cockles of Malaysia (Elhadi et al., 2004). In Turkey, next to V. alginolyticus (>30\%), V. fluvialis was the most common Vibrio in blue crabs and retail fishes (>10\%; Yalcinkaya et al., 2003; Yücel and Balci, 2010).

Generally, fecal pollution has been monitored in aquaculture areas to forecast human pathogens in the products. In Italy, about $11-27 \%$ of the mollusks and shrimps contained $V$. fluvialis without any association between presence of this pathogen and conventional fecal pollution indicators (Ripabelli et al., 2004). The micro fauna and flora occasionally support the occurrence human pathogens. V. fluvialis (36.5\%) was significantly associated with plankton in the effluents of a rural wastewater treatment facility in the Eastern Cape Province of South Africa (Igbinosa et al., 2009). In the Atlantic coast of France, Deter et al. (2010) showed that chlorophyll-A had a significant influence on pathogenic vibrios including $V$. fluvialis in mussels.

There are few reports about identification of $V$. fluvialis from wound infections that took place in recreational areas. Since $V$. fluvialis has been cultured from the teeth of a great white shark (Carcharodon carcharias), there may be an association of this pathogen with wound infections caused by sharks in humans (Buck et al., 1984). Fibropapillomatosis (FP) is a mutilating disease among turtles that cause tumors on the skin and other internal organs. In a study conducted by Aguirre et al. (1994) showed the presence of $V$. fluvialis (47\%) in green turtles with FP.
In the marine environment, $V$. fluvialis plays a major role in the production of hydrogen from starch acquired from the algal mass in the presence of Rhodobium marinum. In co-culture experiments, $V$. fluvialis degrade starch leading to the formation of acetic acid and ethanol, which are subsequently utilized for hydrogen production by $R$. marinum (Ike et al., 1999).

\section{SPORADIC CASES AND OUTBREAKS OF DIARRHEA DUE TO V. fluvialis}

Early reports from the US indicated involvement of $V$. fluvialis with gastroenteritis among infants (Hickman-Brenner et al., 1984; Bellet et al., 1989; Kolb et al., 1997). Since 1979, V. fluvialis was isolated as one of the important pathogens in Tenri Hospital, Japan (Aihara etal., 1991). Prevalence of V. fluvialis among children with diarrhea was very less during 1988 (0.6\%) in Calcutta (now, Kolkata), India (Chatterjee et al., 1989). In the same region, progressive increase in the prevalence of $\mathrm{V}$. fluvialis $(>2 \%)$ among hospitalized acute diarrheal patients has been reported in the following years (Chowdhury et al., 2012). During 1996-1998, prevalence of $V$. fluvialis was 9.4\% among hospitalized diarrheal patients in North Jakarta (Lesmana et al., 2002). In Zhejiang Province, China, V. fluvialis was identified as the second most pathogen (12\%) among acute diarrheal cases but next to V. parahaemolyticus (64\%; Jiang, 1991). Investigations carried out after the 1998 floods in Bangladesh showed involvement of $V$. fluvialis in a diarrhea outbreak (Tanabe et al., 1999). However, the number of cases was less compared to V. cholerae $\mathrm{O} 1$ and $\mathrm{O} 139$ infections.

Vibrio-mediated infections frequently occur in countries where the raw seafood is largely consumed. In many instances, $V$. fluvialis was found to be associated with cholera-like diarrhea (Allton et al., 2006). Between 1982 and 1988, 10 gastroenteritis cases of $V$. fluvialis have been reported in Florida due to consumption of contaminated seafood (Klontz and Desenclos, 1990). In the Gulf coast, the majority of the Vibrio-mediated gastroenteritis has been associated with intake of raw oysters and in about $6 \%$ of the cases $V$. fluvialis was the causative pathogen (Levine and Griffin, 1993). Foodborne outbreaks were reported in several communities implicating $V$. fluvialis alone or with either $V$. parahaemolyticus/Salmonella spp. (Tokoro et al., 1984; Chowdhury et al., 2013).

Foodborne diarrheal outbreaks caused by $V$. fluvialis have been reported during 1981 in Maharashtra (Thekdi et al., 1990) and 2012 in Kolkata (Chowdhury et al., 2013). In Brazil, and USSR, the first report on the association of $V$. fluvialis with diarrhea was reported during 1990 and 1991, respectively (Magalhães et al., 1990; Libinzon etal., 1991). Though the incidence of cholera among high socioeconomic population in Brazil was very low $(0.07 \%)$, but the other vibrios including $V$. fluvialis comparatively prevailed more (1.2\%; Magalhães et al., 1993). In Volga delta, Russia, acute enteric infections caused by $V$. fluvialis reaches about $30 \%$ during the summer months, mainly due to consumption of water than sea/fresh water fishes (Bö̌ko, 2000). Among travelers with diarrheal symptoms, the incidence of $V$. fluvialis seems to be low compared to other enteric pathogens. Early studies conducted with US Peace Corps volunteers in Thailand identified V. fluvialis in about $3 \%$ of the cases (Taylor et al., 1985). 


\section{OTHER INFECTIONS}

Vibrio fluvialis causes a variety of infections in immunecompetent/HIV patients, including bacteremia, biliary tract infection and acute diarrhea (Albert et al., 1991; Usó et al., 2010; Liu et al., 2011). The other rarely reported infections caused by this pathogen include suppurative cholangitis (Yoshii et al., 1987), peritonitis (Lee et al., 2008), acute otitis (Cabrera et al., 2005; Chen et al., 2012) and endophthalmitis (Penland et al., 2000). Large numbers of (29\%) endophthalmitis patients were reported to have mixed infection with V. fluvialis (Hassan et al., 1992). A report from Cuba showed that $V$. fluvialis was one of the predominantly identified pathogens from different extraintestinal samples (Cabrera etal., 2007). Cases of bacteremia with diarrhea (Lai et al., 2006) hemorrhagic cellulitis and cerebritis (Huang and Hsu, 2005), peritonitis (Ratnaraja et al., 2005) have also been reported.

\section{QUORUM SENSING}

Quorum sensing (QS) is a process in which bacterial cells in a population are able to crosstalk with one another, thereby supporting them as a unit to synchronize gene regulation and consequent phenotypic changes. The importance of QS in pathogenic V. cholerae has been well established. Wang et al. (2013) have shown that QS in V. fluvialis regulates two potential virulence factors, including an extracellular protease and hemolysin. In addition, QS also regulates in vitro cytotoxic activity against epithelial cell lines.

\section{VIRULENCE FACTORS}

The clinical as well as environmental $V$. fluvialis strains express many putative virulence factors. The common virulence factor in $V$. fluvialis reported in several investigations is the expression of hemolysin that can be easily identified in sheep-blood agar plates. In majority of the toxin detection assays, eukaryotic cell lines are being used in vitro. In cell-free extracts, $V$. fluvialis has expressed Chinese hamster ovary $(\mathrm{CHO})$ cell elongation factor, $\mathrm{CHO}$ cellkilling factors, cytolysins against erythrocytes and proteases active against azocasein (Lockwood et al., 1982). Various putative virulence factors of $V$. fluvialis are presented in Table 1. However, the ability to produce these factors is not uniform in all the isolates (Liang et al., 2013).

Purification of cytotoxin produced by $V$. fluvialis showed that the protein was heat-labile, and deactivated by proteases. The

Table 1 | Different putative virulence factors described in $V$. fluvialis.

\begin{tabular}{ll}
\hline Factor & Reference \\
\hline Cytolysin & Lockwood et al. (1982) \\
Heat-labile cytotoxin & Wall et al. (1984) \\
Cytotonic & Venkateswaran et al. (1989b) \\
Hemolysin & Wong et al. (1992) \\
Mucinase & Janda (1986) \\
Mannose sensitive & Rahman et al. (1992) \\
hemaagglutination & \\
Cell adherence & Carvalho et al. (1994), Scoglio etal. (2001) \\
Cell vaculation & Chakraborty et al. (2005)
\end{tabular}

culture supernatant retained hemolytic and phospholipase A2 activities and were coeluted in the gel filtration (Wall et al., 1984). The purified extracellular hemolysin produced by $V$. fluvialis showed virulence features including lyses of erythrocytes of different animal origin and activation of fluid accumulation in suckling mice (Han et al., 2002; Kothary et al., 2003).

The transmembrane regulatory protein (ToxR) is essential for the expression of virulence factors in pathogenic vibrios. Similar to $V$. cholerae, the ToxR plays a major role in bile resistance of $V$. fluvialis, which is an initial phase in the progression of vibrios as potential intestinal pathogens (Provenzano et al., 2000). Adaptability of vibrios to the intestinal environment, especially the bile salts favors colonization and expression of virulence factors. After initial adaptation to the bile salts under in vitro conditions, the $V$. fluvialis exhibited swarming mobility, biofilm formation and adherence (Di Pietro et al., 2004). In the animal models, V. fluvialis and the cholera toxin $(\mathrm{CT})$ produced by $V$. cholerae $\mathrm{O} 1$ strains confirmed skin permeability factor (SPF). However, the antibodies against CT did not neutralize the SPF of $V$. fluvialis (Rodrigues et al., 1993; Ahsan et al., 1988).

The exocellular metalloprotease produced by $V$. fluvialis (VFP) was found to be similar to the one produced by $V$. vulnificus, which has also been used for the hemagglutination activity (Miyoshi et al., 2002). In addition, the amino acid sequence of VFP was found to be a member of the thermolysin family. It is interesting to note that most of the $V$. fluvialis isolated from the diarrheal patients harbored genes encoding hemolysin and metalloprotease (Chowdhury et al., 2012).

\section{SURVIVAL}

Vibrio fluvialis has the capacity to survive in the seawater microcosm for more than 15 days at ambient temperature regardless of carbonated substrate uptake (Munro et al., 1994). In microcosms, $V$. fluvialis has been shown culturally viable for a year without losing its virulence and in sediments this organism was recovered from viable but non-culturable stage, even after 6 years (Amel et al., 2008).

\section{ANTIMICROBIAL RESISTANCE}

Compared to other clinical vibrios, antimicrobial resistance (AMR) is largely reported in V. fluvialis. In Mediterranean fish farms, many of the vibrios including $V$. fluvialis were resistant to ampicillin, carbenicillin, kanamycin, cefalotin, and sulfadiazine-trimethoprim (Laganà et al., 2011). In South Africa, treated effluent system was found to be the reservoir for $V$. fluvialis strains, which are resistant to ampicillin, penicillin-G, streptomycin, sulfamethoxazole, trimethoprim, chloramphenicol, erythromycin, ciprofloxacin, and polymyxin B (Igbinosa et al., 2011b). In China, majority of the $V$. fluvialis strains were resistant for $\beta$-lactams, azithromycin, and sulfamethoxazole (Liang et al., 2013).

Several mobile genetic elements carrying AMR have been found in $V$. fluvialis. The integrative and conjugative element (ICE) is a conjugative transposon commonly detected in $V$. cholerae, which carries resistance genes for sulfamethoxazole-trimethoprim (SXT), chloramphenicol and streptomycin (Srinivasan et al., 2006; Taviani etal., 2008). This SXT element has also been reported 
in $V$. fluvialis that has integrase gene similar to that of $V$. cholerae (Ahmed et al., 2005). The aminoglycoside acetyltransferase encoding gene $\operatorname{aac}(3)$-Id was identified in class 1 integron from a clinical V. fluvialis strains (Ahmed et al., 2004).

Transfer of large plasmids carrying AMR genes is rarely detected in V. fluvialis (Rajpara et al., 2009). Efflux systems responsible for nalidixic acid and ciprofloxacin resistance have been reported in several clinical V. fluvialis strains (Srinivasan et al., 2006). Two putative multi antimicrobial extrusion (MATE) protein family efflux pumps viz., $\mathrm{H}$ - and D-type were found to be responsible for fluoroquinolones resistance in $V$. fluvialis. The sequences of these MATE encoding genes were found to be $~ 99 \%$ identical to $V$. cholerae (Mohanty et al., 2012). In addition, many $V$. fluvialis strains had mutation (serine to isoleucine) at position 83 of the quinolone resistance-determining region (QRDR) of gyrA. Apart from this mutation, presence of plasmid-borne qnrVC-like genes have been reported for quinolone resistance in some of the $V$. fluvialis strains (Singh et al., 2012). V. fluvialis isolated from diarrheal patients in Kolkata were resistant to fluoroquinolones and $\beta$-lactam antimicrobials had mutations in the QRDR of GyrA at position 83 and of ParC at position 85 (Chowdhury et al., 2011). In addition, these strains carried a transferrable $150-\mathrm{kb}$ plasmid that harbored the quinolone resistance qnrA1 in a complex sull-type integron, the ciprofloxacin-modifying enzyme-encoding gene $a a c(6)-I b-c r$ and genes encoding for extended-spectrum $\beta$-lactamases such as bla $a_{S H V}$ and $b l a_{C T X-M-3}$.

\section{CONCLUSION}

Though the pathogen $V$. fluvialis has known for quite some time, its clinical importance is realized now, as the prevalence of diarrhea cases is reportedly increasing. In depth studies on the pathogenesis of $V$. fluvialis has to be established as there are many descriptions about the putative virulence factor.

\section{ACKNOWLEDGMENTS}

This work was supported by the Japan Initiative for Global Research Network for Infectious Diseases, Ministry of Education, Culture, Sports, Science and Technology, Japan.

\section{REFERENCES}

Aguirre, A. A., Balazs, G. H., Zimmerman, B., and Spraker, T. R. (1994). Evaluation of Hawaiian green turtles (Chelonia mydas) for potential pathogens associated with fibropapillomas. J. Wildl. Dis. 30, 8-15. doi: 10.7589/0090-3558-30.1.8

Ahmed, A. M., Nakagawa, T., Arakawa, E., Ramamurthy, T., Shinoda, S., and Shimamoto, T. (2004). New aminoglycoside acetyltransferase gene, aac(3)-Id, in a class 1 integron from a multiresistant strain of Vibrio fluvialis isolated from an infant aged 6 months. J. Antimicrob. Chemother. 53, 947-951. doi: 10.1093/jac/dkh221

Ahmed, A. M., Shinoda, S., and Shimamoto, T. (2005). A variant type of Vibrio cholerae SXT element in a multidrug-resistant strain of Vibrio fluvialis. FEMS Microbiol. Lett. 242, 241-247. doi: 10.1016/j.femsle.2004.11.012

Ahsan, C. R., Sanyal, S. C., Zaman, A., Neogy, P. K., and Huq, M. I. (1988). Immunobiological relationships between Vibrio fluvialis and Vibrio cholerae enterotoxins. Immunol. Cell Biol. 66, 251-252. doi: 10.1038/icb.1988.32

Aihara, M., Sakai, M., Iwasaki, M., Shimakawa, K., Kozaki, S., Kubo, M., et al. (1991). Isolation of enteropathogenic microorganism from patients with infection of the digestive tract during 1976 to 1988 in Tenri Hospital. Kansenshogaku Zasshi 65, 864-874. [In Japanese].

Albert, M. J., Hossain, M. A., Alam, K., Kabir, I., Neogi, P. K., and Tzipori, S. (1991). A fatal case associated with shigellosis and Vibrio fluvialis bacteremia. Diagn. Microbiol. Infect. Dis. 14, 509-510. doi: 10.1016/0732-8893(91)90008-4
Allton, D. R., Forgione, M. A. Jr., and Gros, S. P. (2006). Cholera-like presentation in Vibrio fluvialis enteritis. South Med. J. 99, 765-767. doi: 10.1097/01.smj.0000223657.22296.e6

Amel, B. K., Amine, B., and Amina, B. (2008). Survival of Vibrio fluvialis in seawater under starvation conditions. Microbiol. Res. 163, 323-328. doi: 10.1016/j.micres.2006.06.006

Bellet, J., Klein, B., Altieri, M., and Ochsenschlager, D. (1989). Vibrio fluvialis, an unusual pediatric enteric pathogen. Pediatr. Emerg. Care 5, 27-28. doi: 10.1097/00006565-198903000-00008

Boiko, A. V. (2000). The etiological structure of acute intestinal infections caused by noncholera vibrios in the Volga delta. Zh. Mikrobiol. Epidemiol. Immunobiol. 1, 15-17. [In Russian].

Brenner, D. J., Hickman-Brenner, F. W., Lee, J. V., Steigerwalt, A. G., Fanning, G. R., Hollis, D. G., et al. (1983). Vibrio furnissii (formerly aerogenic biogroup of Vibrio fluvialis), a new species isolated from human feces and the environment. J. Clin. Microbiol. 18, 816-824.

Buck, J. D., Spotte, S., and Gadbaw, J. J. Jr. (1984). Bacteriology of the teeth from a great white shark: potential medical implications for shark bite victims. J. Clin. Microbiol. 20, 849-851.

Cabrera, R. L. E., Castro, E. G., Ramírez, A. M. M., Llop, H. A., Llanes, C. R., Castañeda, E. N., et al. (2007). Isolation and identification of species from the genera Aeromonas, Vibrio, and Plesiomonas from extraintestinal samples in Cuba. Rev. Chilena Infectol. 24, 204-208. [In Spanish]. doi: 10.4067/S071610182007000300005

Cabrera, R. L. E., Monroy, S. P., Morier, L., Ramírez, A. M. M., Fernández, A. A., Castro, E. G., et al. (2005). Severe otitis due to Vibrio fluvialis in a patient with AIDs: first report in the world. Rev. Cubana Med. Trop. 57, 154-155.

Carvalho, I. T., Magalhães, V., Leal, N. C., Melo, V., and Magalhães, M. (1994). Vibrio fluvialis attaches to but does not enter HeLa cell monolayers. Mem. Inst. Oswaldo Cruz 89, 221-223. doi: 10.1590/S0074-02761994000200019

Centers for Disease Control and Prevention (CDC). (2013). Incidence, and trends of infection with pathogens transmitted commonly through food - foodborne diseases active surveillance network, 10 U.S. sites, 1996-2012. MMWR Morb. Mortal Wkly. Rep. 62, 283-287.

Chakraborty, R., Chakraborty, S., De, K., Sinha, S., Mukhopadhyay, A. K., Khanam, J., et al. (2005). Cytotoxic and cell vacuolating activity of Vibrio fluvialis isolated from paediatric patients with diarrhoea. J. Med. Microbiol. 54(Pt 8), 707-716. doi: 10.1099/jmm.0.45820-0

Chakraborty, R., Sinha, S., Mukhopadhyay, A. K., Asakura, M., Yamasaki, S., Bhattacharya, S. K., et al. (2006). Species-specific identification of Vibrio fluvialis by PCR targeted to the conserved transcriptional activation and variable membrane tether regions of the toxR gene. J. Med. Microbiol. 55, 805-808. doi: 10.1099/jmm.0.46395-0

Chan, K. Y., Woo, M. L., Lam, L. Y., and French, G. L. (1989). Vibrio parahaemolyticus and other halophilic vibrios associated with seafood in Hong Kong. J. Appl. Bacteriol. 66, 57-64. doi: 10.1111/j.1365-2672.1989.tb02454.x

Chan, K. Y., Woo, M. L., Lo, K. W., and French, G. L. (1986). Occurrence and distribution of halophilic vibrios in subtropical coastal waters of Hong Kong. Appl. Environ. Microbiol. 52, 1407-1411.

Chatterjee, B. D., Thawani, G., and Sanyal, S. N. (1989). Etiology of acute childhood diarrhoea in Calcutta. Trop. Gastroenterol. 10, 158-166.

Chen, K., Lin, Y., and Chen, G. (1995). Studies on diagnostic bacteriophage of Vibrio fluvialis. Zhonghua Yu Fang Yi Xue Za Zhi 29, 138-140.

Chen, P. J., Tseng, C. C., Chan, H. T., and Chao, C. M. (2012). Acute otitis due to Vibrio fluvialis after swimming. Case Rep. Emerg. Med. 2012, 838904. doi: 10.1155/2012/838904

Chowdhury, G., Pazhani, G. P., Dutta, D., Guin, S., Dutta, S., Ghosh, S., et al. (2012). Vibrio fluvialis in patients with diarrhea, Kolkata, India. Emerg. Infect. Dis. 18, 1868-1871. doi: 10.3201/eid1811.120520

Chowdhury, G., Pazhani, G. P., Nair, G. B., Ghosh, A., and Ramamurthy, T. (2011). Transferable plasmid-mediated quinolone resistance in association with extended-spectrum $\beta$-lactamases and fluoroquinolone-acetylating aminoglycoside-6'-N-acetyltransferase in clinical isolates of Vibrio fluvialis. Int. J. Antimicrob. Agents 38, 169-173. doi: 10.1016/j.ijantimicag.2011. 04.013

Chowdhury, G., Sarkar, A., Pazhani, G. P., Mukhopadhyay, A. K., Bhattacharya, M. K., and Ramamurthy, T. (2013). An outbreak of foodborne gastroenteritis 
caused by dual pathogens, Salmonella enterica serovar Weltevreden and Vibrio fluvialis in Kolkata, India. Foodborne Pathog. Dis. 10, 904-906. doi: 10.1089/fpd. 2013.1491

Ciznãr, I., Hussain, N., Ahsan, C. R., Kay, B. A., Clemens, J. D., and Sack, D. A. (1989). Oral cholera vaccines containing B-subunit-killed whole cells and killed whole cells only. I. Cross-reacting antigens of members of family Vibrionaceae and the vaccines. Vaccine 7, 111-116. doi: 10.1016/0264-410X(89)90047-9

Dalmasso, A., Civera, T., and Bottero, M. T. (2009). Multiplex primer-extension assay for identification of six pathogenic vibrios. Int. J. Food Microbiol. 129, 21-25. doi: 10.1016/j.ijfoodmicro.2008.10.029

De, A., Sen, P. C., and Tewari, I. C. (1993). Enteropathogenic bacteria in river Ganges in Varanasi. Indian J. Pathol. Microbiol. 36, 425-432.

Deter, J., Lozach, S., Derrien, A., Véron, A., Chollet, J., and Hervio-Heath, D. (2010). Chlorophyll a might structure a community of potentially pathogenic culturable Vibrionaceae. Insights from a one-year study of water and mussels surveyed on the French Atlantic coast. Environ. Microbiol. Rep. 2, 185-191. doi: 10.1111/j.1758-2229.2010.00133.x

Di Pietro, A., Picerno, I., Visalli, G., Chirico, C., and Scoglio, M. E. (2004). Effects of "host factor" bile on adaptability and virulence of vibrios, foodborne potential pathogenic agents. Ann. Ig. 16, 615-625. [In Italian].

Dumontet, S., Krovacek, K., Svenson, S. B., Pasquale, V., Baloda, S. B., and Figliuolo, G. (2000). Prevalence and diversity of Aeromonas and Vibrio spp. in coastal waters of Southern Italy. Comp. Immunol. Microbiol. Infect. Dis. 23, 53-72. doi: 10.1016/S0147-9571(99)00059-4

Elhadi, N., Radu, S., Chen, C. H., and Nishibuchi, M. (2004). Prevalence of potentially pathogenic Vibrio species in the seafood marketed in Malaysia. J. Food Prot. $67,1469-1475$

Franco, P. F., and Hedreyda, C. T. (2006). Amplification and sequence analysis of the full length toxR gene in Vibrio harveyi. J. Gen. Appl. Microbiol. 52, 281-287. doi: 10.2323/jgam.52.281

García, C. V., and Antillón, F. (1990). Isolation of enteropathogenic Vibrio in bivalves and mud from the Nicoya Gulf, Costa Rica. Rev. Biol. Trop. 138, 437-440. [In Spanish].

Han, J. H., Lee, J. H., Choi, Y. H., Park, J. H., Choi, T. J., and Kong, I. S. (2002). Purification, characterization and molecular cloning of Vibrio fluvialis hemolysin. Biochim. Biophys. Acta 1599, 106-114. doi: 10.1016/S1570-9639(02)00 407-7

Hassan, I. J., MacGowan, A. P., and Cook, S. D. (1992). Endophthalmitis at the Bristol Eye Hospital: an 11-year review of 47 patients. J. Hosp. Infect. 22, 271-278. doi: 10.1016/0195-6701(92)90012-B

Hickman-Brenner, F. W., Brenner, D. J., Steigerwalt, A. G., Schreiber, M., Holmberg, S. D., Baldy, L. M., et al. (1984). Vibrio fluvialis and Vibrio furnissii isolated from a stool sample of one patient. J. Clin. Microbiol. 20, 125-127.

Hoge, C. W., Watsky, D., Peeler, R. N., Libonati, J. P., Israel, E., and Morris, J. G. Jr. (1989). Epidemiology and spectrum of Vibrio infections in a Chesapeake Bay community. J. Infect. Dis. 160, 985-993. doi: 10.1093/infdis/160.6.985

Huang, K. C., and Hsu, R. W. (2005). Vibrio fluvialis hemorrhagic cellulitis and cerebritis. Clin. Infect. Dis. 40, 75-77. doi: 10.1086/429328

Igbinosa, E. O., Obi, L. C., and Okoh, A. I. (2009). Occurrence of potentially pathogenic vibrios in final effluents of a wastewater treatment facility in a rural community of the Eastern Cape Province of South Africa. Res. Microbiol. 160, 531-537. doi: 10.1016/j.resmic.2009.08.007

Igbinosa, E. O., Obi, C. L., and Okoh, A. I. (2011a). Seasonal abundance and distribution of Vibrio species in the treated effluent of wastewater treatment facilities in suburban and urban communities of Eastern Cape Province, South Africa. J. Microbiol. 49, 224-232. doi: 10.1007/s12275-0110227-x

Igbinosa, E. O., Obi, L. C., Tom, M., and Okoh, A. I. (2011b). Detection of potential risk of wastewater effluents for transmission of antibiotic resistance from Vibrio species as a reservoir in a peri-urban community in South Africa. Int. J. Environ. Health Res. 21, 402-414. doi: 10.1080/09603123.2011.572278

Iguchi, T., Kondo, S., and Hisatsune, K. (1993). A chemotaxonomic study of Vibrio fluvialis based on the sugar composition of the polysaccharide portion of the lipopolysaccharides. Microbiol. Immunol. 37, 153-157. doi: 10.1111/j.1348-0421.1993.tb03193.x

Ike, A., Murakawa, T., Kawaguchi, H., Hirata, K., and Miyamoto, K. (1999). Photoproduction of hydrogen from raw starch using a halophilic bacterial community. J. Biosci. Bioeng. 88, 72-77. doi: 10.1016/S1389-1723(99)80179-0
Israil, A. M., Balotescu, M. C., Alexandru, I., and Dobre, G. (2003). Discordancies between classical and API 20E microtest biochemical identification of Vibrio and Aeromonas strains. Bacteriol. Virusol. Parazitol. Epidemiol. 48, 141-143.

Janda, J. M. (1986). Mucinase activity among selected members of the family Vibrionaceae. Microb. Lett. 33, 19-22.

Ji, N., Peng, B., Wang, G., Wang, S., and Peng, X. (2004). Universal primer PCR with DGGE for rapid detection of bacterial pathogens. J. Microbiol. Methods 57, 409-413. doi: 10.1016/j.mimet.2004.02.010

Jiang, W. P. (1991). A study on diarrhoea disease caused by Vibrionaceae along coast the east of Zhejiang Province. Zhonghua Yu Fang Yi Xue Za Zhi 25, 335-337. [In Chinese].

Kelly, M. T., and Stroh, E. M. (1988). Occurrence of Vibrionaceae in natural and cultivated oyster populations in the Pacific Northwest. Diagn. Microbiol. Infect. Dis. 9, 1-5. doi: 10.1016/0732-8893(88)90054-5

Klontz, K. C., and Desenclos, J. C. (1990). Clinical and epidemiological features of sporadic infections with Vibrio fluvialis in Florida, USA. J. Diarrhoeal Dis. Res. 8, $24-26$.

Kolb, E. A., Eppes, S. C., and Klein, J. D. (1997). Vibrio fluvialis: an underrecognized enteric pathogen in infants? South Med. J. 90, 544-545. doi: 10.1097/00007611199705000-00017

Kondo, S., Haishima, Y., Ishida, K., Isshiki, Y., and Hisatsune, K. (2000). The O-polysaccharide of lipopolysaccharide isolated from Vibrio fluvialis O19 is identical to that of Vibrio bioserogroup 1875 variant. Microbiol. Immunol. 44, 941-944. doi: 10.1111/j.1348-0421.2000.tb02586.x

Kothary, M. H., Lowman, H., McCardell, B. A., and Tall, B. D. (2003). Purification and characterization of enterotoxigenic El Tor-like hemolysin produced by Vibrio fluvialis. Infect. Immun. 71, 3213-3220. doi: 10.1128/IAI.71.6.3213-32 20.2003

Laganà, P., Caruso, G., Minutoli, E., Zaccone, R., and Santi, D. (2011). Susceptibility to antibiotics of Vibrio spp. and Photobacterium damsela ssp. piscicida strains isolated from Italian aquaculture farms. New Microbiol. 34, 53-63.

Lai, C. H., Hwang, C. K., Chin, C., Lin, H. H., Wong, W. W., and Liu, C. Y. (2006). Severe watery diarrhoea and bacteraemia caused by Vibrio fluvialis. J. Infect. 52, e95-e98. doi: 10.1016/j.jinf.2005.05.023

Lee, C. Y., Hong, Y., Ryu, J., Kim, Y. R., Oh, S. S., Lee, S. H., et al. (2012). Detection and identification of Vibrio species using whole-cell protein pattern analysis. J. Microbiol. Biotechnol. 22, 1107-1112. doi: 10.4014/jmb.1201.01001

Lee, J. V., Shread, P., Furniss, A. L., and Bryant, T. N. (1981). Taxonomy and description of Vibrio fluvialis sp. nov. (synonym group F vibrios, group EF6). J. Appl. Bacteriol. 50, 73-94. doi: 10.1111/j.1365-2672.1981.tb00873.x

Lee, J. Y., Park, J. S., Oh, S. H., Kim, H. R., Lee, J. N., and Shin, J. H. (2008). Acute infectious peritonitis caused by Vibrio fluvialis. Diagn. Microbiol. Infect. Dis. 62, 216-218. doi: 10.1016/j.diagmicrobio.2008.05.012

Lee, S. K., Wang, H. Z., Law, S. H., Wu, R. S., and Kong, R. Y. (2002). Analysis of the 16S-23S rDNA intergenic spacers (IGSs) of marine vibrios for species-specific signature DNA sequences. Mar. Pollut. Bull. 44, 412-420. doi: 10.1016/S0025326X(01)00256-9

Lesmana, M., Subekti, D. S., Tjaniadi, P., Simanjuntak, C. H., Punjabi, N. H., Campbell, J. R., et al. (2002). Spectrum of Vibrio species associated with acute diarrhea in North Jakarta, Indonesia. Diagn. Microbiol. Infect. Dis. 43, 91-97. doi: 10.1016/S0732-8893(02)00373-5

Levine, W. C., and Griffin, P. M. (1993). Vibrio infections on the Gulf Coast: results of first year of regional surveillance. Gulf Coast Vibrio Working Group. J. Infect. Dis. 167, 479-483.

Li, Y. D., Ren, H. L., Lu, S. Y., Zhou, Y., Han, X., Gong, B. B., et al. (2010). Cloning, expression, and genus-specificity analysis of $28-\mathrm{kDa}$ OmpK from Vibrio alginolyticus. J. Food Sci. 75, 198-203. doi: 10.1111/j.1750-3841.2010.01565.x

Liang, P., Cui, X., Du, X., Kan, B., and Liang, W. (2013). The virulence phenotypes and molecular epidemiological characteristics of Vibrio fluvialis in China. Gut Pathog. 5, 6. doi: 10.1186/1757-4749-5-6

Libinzon, A. E., Levanova, G. F., and Gal'tseva, G. V. (1991). The isolation of Vibrio fluvialis on the territory of the USSR. Zh. Mikrobiol. Epidemiol. Immunobiol. 2, 20-23. [In Russian].

Liu, W. L., Chiu, Y. H., Chao, C. M., Hou, C. C., and Lai, C. C. (2011). Biliary tract infection caused by Vibrio fluvialis in an immunocompromised patient. Infection 39, 495-496. doi: 10.1007/s15010-011-0146-0

Lockwood, D. E., Kreger, A. S., and Richardson, S. H. (1982). Detection of toxins produced by Vibrio fluvialis. Infect. Immun. 35, 702-708. 
Magalhães, V., Lima, R. A., Magalhães, E., and Magalhães, M. (1990). Human gastroenteritis associated with Vibrio fluvialis in Recife. Arq. Gastroenterol. 27, 141-143. [In Portuguese].

Magalhães, V., Magalhães, M., and Marques, L. R. (1993). Vibrios among patients of good socioeconomic conditions during the cholera epidemic in Recife, Brazil. Rev. Inst. Med. Trop. Sao Paulo 35, 345-346. doi: 10.1590/S0036-466519930004 00007

Martin, Y. P., and Bonnefont, J. L. (1990). Annual variations and identification of Vibrios growing at 37 degrees $\mathrm{C}$ in urban sewage, in mussels and in seawater at Toulon harbour (Mediterranean, France). Can. J. Microbiol. 36, 47-52. doi: 10.1139/m90-008

Matté, G. R., Matté, M. H., Sato, M. I., Sanchez, P. S., Rivera, I. G., and Martins, M. T. (1994). Potentially pathogenic vibrios associated with mussels from a tropical region on the Atlantic coast of Brazil. J. Appl. Bacteriol. 77, 281-287. doi: 10.1111/j.1365-2672.1994.tb03075.x

Miyoshi, S., Sonoda, Y., Wakiyama, H., Rahman, M. M., Tomochika, K., Shinoda S., et al. (2002). An exocellular thermolysin-like metalloprotease produced by Vibrio fluvialis: purification, characterization, and gene cloning. Microb. Pathog. 33, 127-134. doi: 10.1006/mpat.2002.0520

Mohanty, P., Patel, A., and Bhardwaj, A. K. (2012). Role of H- and DMATE-type transporters from multidrug resistant clinical isolates of Vibrio fluvialis in conferring fluoroquinolone resistance. PLOS ONE 7:e35752. doi: 10.1371/journal.pone.0035752

Munro, P. M., Brahic, G., and Clément, R. L. (1994). Seawater effects on various Vibrio species. Microbios 77, 191-198.

Myatt, D. C., and Davis, G. H. (1989). Isolation of medically significant Vibrio species from riverine sources in south east Queensland. Microbios 60, 111-123.

O’Hara, C. M., Sowers, E. G., Bopp, C. A., Duda, S. B., and Strockbine, N. A. (2003). Accuracy of six commercially available systems for identification of members of the family Vibrionaceae. J. Clin. Microbiol. 41, 5654-5659. doi: 10.1128/JCM.41.12.5654-5659.2003

Oo, K. N., Myint, T., New, Y. Y., and Aye, T. (1993). Vibrio spp. isolated from natural waters of the city of Yangon, Myanmar. J. Diarrhoeal Dis. Res. 11, 105-107.

Pedersen, K., Austin, B., Austin, D. A., and Larsen, J. L. (1999). Vibrios associated with mortality in cultured plaice Pleuronectes platessa fry. Acta Vet. Scand. 40 263-270.

Penland, R. L., Boniuk, M., and Wilhelmus, K. R. (2000). Vibrio ocular infections on the U.S. Gulf Coast. Cornea 19, 26-29. doi: 10.1097/00003226-200001000-00006

Provenzano, D., Schuhmacher, D. A., Barker, J. L., and Klose, K. E. (2000). The virulence regulatory protein ToxR mediates enhanced bile resistance in Vibrio cholerae and other pathogenic Vibrio species. Infect. Immun. 68, 1491-1497. doi: 10.1128/IAI.68.3.1491-1497.2000

Rahman, M. M., Qadri, F., Albert, M. J., Hossain, A., and Mosihuzzaman, M. (1992). Lipopolysaccharide composition and virulence properties of clinical and environmental strains of Vibrio fluvialis and Vibrio mimicus. Microbiol. Immunol. 36, 327-338. doi: 10.1111/j.1348-0421.1992.tb02032.x

Rajpara, N., Patel, A., Tiwari, N., Bahuguna, J., Antony, A., Choudhury, I., et al. (2009). Mechanism of drug resistance in a clinical isolate of Vibrio fluvialis: involvement of multiple plasmids and integrons. Int. J. Antimicrob. Agents 34, 220-225. doi: 10.1016/j.ijantimicag.2009.03.020

Ratnaraja, N., Blackmore, T., Byrne, J., and Shi, S. (2005). Vibrio fluvialis peritonitis in a patient receiving continuous ambulatory peritoneal dialysis. J. Clin. Microbiol. 43, 514-515. doi: 10.1128/JCM.43.1.514-515.2005

Ripabelli, G., Sammarco, M. L., Fanelli, I., and Grasso, G. M. (2004). Detection of Salmonella, Listeria spp., Vibrio spp., and Yersinia enterocolitica in frozen seafood and comparison with enumeration for faecal indicators: implication for public health. Ann. Ig. 16, 531-539. [In Italian].

Rodrigues, D. P., Ribeiro, R. V., Alves, R. M., and Hofer, E. (1993). Evaluation of virulence factors in environmental isolates of Vibrio species. Mem. Inst. Oswaldo Cruz 88, 589-592. doi: 10.1590/S0074-02761993000400016

Schandevyl, P., Van, D. E., and Piot, P. (1984). Halophilic Vibrio species from seafish in Senegal. Appl. Environ. Microbiol. 48, 236-238.

Scoglio, M. E., Di Pietro, A., Picerno, I., Delia, S., Mauro, A., and Lagana, P. (2001). Virulence factors in vibrios and aeromonads isolated from seafood. New Microbiol. 24, 273-280.

Shimada, T., Arakawa, E., Okitsu, T., Yamai, S., Matsushita, S., Kudoh, Y., et al. (1999). Additional O antigens of Vibrio fluvialis and Vibrio furnissii. Jpn. J. Infect. Dis. 52, 124-126.
Shimada, T., Sakazaki, R., and Tobita, K. (1987). Vibrio fluvialis: a new serogroup (19) possessing the Inaba factor antigen of Vibrio cholerae O1. Jpn. J. Med. Sci. Biol. 40, 153-157.

Shinoda, S., Nakahara, N., and Kane, H. (1984). Lateral flagellum of Vibrio fluvialis: a species-specific antigen. Can. J. Microbiol.30, 1525-1529. doi: 10.1139/m84-242 Shinoda, S., Yakiyama, I., Yasui, S., Kim, Y. M., Ono, B., and Nakagami, S. (1992). Lateral flagella of vibrios: serological classification and genetical similarity. Microbiol. Immunol. 36, 303-309. doi: 10.1111/j.1348-0421.1992. tb01667.x

Singh, R., Rajpara, N., Tak, J., Patel, A., Mohanty, P., Vinothkumar, K., et al. (2012). Clinical isolates of Vibrio fluvialis from Kolkata, India, obtained during 2006: plasmids, the qnr gene and a mutation in gyrase A as mechanisms of multidrug resistance. J. Med. Microbiol. 61(Pt 3), 369-374. doi: 10.1099/jmm.0.03 7226-0

Srinivasan, V. B., Virk, R. K., Kaundal, A., Chakraborty, R., Datta, B., Ramamurthy, T., et al. (2006). Mechanism of drug resistance in clonally related clinical isolates of Vibrio fluvialis isolated in Kolkata, India. Antimicrob. Agents Chemother. 50, 2428-2432. doi: 10.1128/AAC.01561-05

Suthienkul, O. (1993). Bacteriophage typing of Vibrio fluvialis. Southeast Asian J. Trop. Med. Public Health 24, 449-454.

Tanabe, K., Nakamura, S., and Kunii, O. (1999). Bacteriological survey of diarrheal epidemics in the 1998 Bangladesh floods. Kansenshogaku Zasshi 73, 918-919. [In Japanese].

Tassin, M. G., Siebeling, R. J., Roberts, N. C., and Larson, A. D. (1983). Presumptive identification of Vibrio species with H antiserum. J. Clin. Microbiol. 18, 400-407.

Taviani, E., Ceccarelli, D., Lazaro, N., Bani, S., Cappuccinelli, P., Colwell, R. R., etal. (2008). Environmental Vibrio spp., isolated in Mozambique, contain a polymorphic group of integrative conjugative elements and class 1 integrons. FEMS Microbiol. Ecol. 64, 45-54. doi: 10.1111/j.1574-6941.2008. 00455.x

Taylor, D. N., Echeverria, P., Blaser, M. J., Pitarangsi, C., Blacklow, N., Cross, J., et al. (1985). Polymicrobial aetiology of travellers' diarrhoea. Lancet 1, 381-383. doi: 10.1016/S0140-6736(85)91397-2

Thekdi, R. J., Lakhani, A. G., Rale, V. B., and Panse, M. V. (1990). An outbreak of food poisoning suspected to be caused by Vibrio fluvialis. J. Diarrhoeal Dis. Res. 8, 163-165.

Tokoro, M., Kato, M., Goto, K., Watanabe, M., Yamada, F., Sako, T., et al. (1984). Community outbreaks of mixed food-borne infection with Vibrio parahaemolyticus and Vibrio fluvialis. Kansenshogaku Zasshi 58, 1038-1045. [In Japanese]

Uchiyama, H. (2000). Distribution of Vibrio species isolated from aquatic environments with TCBS agar. Environ. Health Prev. Med. 4, 199-204. doi: 10.1007/BF02931258

Usó, J., Tirado, M. D., Moreno, R., and Campos, A. (2010). Vibrio fluvialis diarrhoea in an HIV infected patient. Enferm. Infecc. Microbiol. Clin. 28, 748-789. doi: 10.1016/j.eimc.2010.02.020

Venkateswaran, K., Nakano, H., Okabe, T., Takayama, K., Matsuda, O., and Hashimoto, H. (1989a). Occurrence and distribution of Vibrio spp., Listonella spp., and Clostridium botulinum in the Seto Inland Sea of Japan. Appl. Environ. Microbiol. 55, 559-567.

Venkateswaran, K., Kiiyukia, C., Takaki, M., Nakano, H., Matsuda, H., Kawakami, H., etal. (1989b). Characterization of toxigenic vibrios isolated from the freshwater environment of Hiroshima, Japan. Appl. Environ. Microbiol. 55, 2613-2618.

Vinothkumar, K., Bhardwaj, A. K., Ramamurthy, T., and Niyogi, S. K. (2013). Triplex PCR assay for the rapid identification of 3 major Vibrio species, Vibrio cholerae, Vibrio parahaemolyticus, and Vibrio fluvialis. Diagn. Microbiol. Infect. Dis. 76, 526-528. doi: 10.1016/j.diagmicrobio.2013. 04.005

Wall, V. W., Kreger, A. S., and Richardson, S. H. (1984). Production and partial characterization of a Vibrio fluvialis cytotoxin. Infect. Immun. 46, 773-777.

Wang, Y., Wang, H., Liang, W., Hay, A. J., Zhong, Z., Kan, B., et al. (2013). Quorum sensing regulatory cascades control Vibrio fluvialis pathogenesis. J. Bacteriol. 195, 3583-3589. doi: 10.1128/JB.00508-13

Wilkes, J. G., Rushing, L. G., Gagnon, J. F., McCarthy, S. A., Rafii, F., Khan, A. A., et al. (2005). Rapid phenotypic characterization of Vibrio isolates by pyrolysis metastable atom bombardment mass spectrometry. Antonie Van Leeuwenhoek 88, 151-161. doi: 10.1007/s10482-005-3990-Z 
Williams, L. A., and Larock, P. A. (1985). Temporal occurrence of Vibrio species and Aeromonas hydrophila in estuarine sediments. Appl. Environ. Microbiol. 50, 1490-1495.

Wong, H. C., Ting, S. H., and Shieh, W. R. (1992). Incidence of toxigenic vibrios in foods available in Taiwan. J. Appl. Bacteriol. 73, 197-202. doi: 10.1111/j.13652672.1992.tb02978.x

Yalcinkaya, F., Ergin, C., Agalar, C., Kaya, S., and Aksoylar, M. Y. (2003). The presence and antimicrobial susceptibilities of human-pathogen Vibrio spp. isolated from blue crab (Callinectes sapidus) in Belek tourism coast, Turkey. Int. J. Environ. Health Res. 13, 95-98. doi: 10.1080/09603120210000 63304

Yoshii, Y., Nishino, H., Satake, K., and Umeyama, K. (1987). Isolation of Vibrio fluvialis, and unusual pathogen in acute suppurative cholangitis. Am. J. Gastroenterol. 82, 903-905.

Yücel, N., and Balci, S. (2010). Prevalence of Listeria, Aeromonas, and Vibrio species in fish used for human consumption in Turkey. J. Food Prot. 73 380-384.
Conflict of Interest Statement: The authors declare that the research was conducted in the absence of any commercial or financial relationships that could be construed as a potential conflict of interest.

Received: 17 December 2013; accepted: 19 February 2014; published online: 07 March 2014.

Citation: Ramamurthy T, Chowdhury G, Pazhani GP and Shinoda S (2014) Vibrio fluvialis: an emerging human pathogen. Front. Microbiol. 5:91. doi: 10.3389/fmicb.2014.00091

This article was submitted to Aquatic Microbiology, a section of the journal Frontiers in Microbiology.

Copyright (c) 2014 Ramamurthy, Chowdhury, Pazhani and Shinoda. This is an openaccess article distributed under the terms of the Creative Commons Attribution License (CC BY). The use, distribution or reproduction in other forums is permitted, provided the original author(s) or licensor are credited and that the original publication in this journal is cited, in accordance with accepted academic practice. No use, distribution or reproduction is permitted which does not comply with these terms. 